\title{
Automated Pheresis
}

National Cancer Institute

\section{Source}

National Cancer Institute. Automated Pheresis. NCI Thesaurus. Code C133333.

The procurement of red blood cells, platelets, leukocytes, granulocytes, or plasma by automated equipment. 